JPE 11-1-3

\title{
Zero-Voltage-Switching Boost Converter Using a Coupled Inductor
}

\author{
Hyun-Lark Do ${ }^{\dagger}$ \\ $\dagger^{\dagger}$ Dept. of Electronic and Information Eng., Seoul National University of Science and Technology, Seoul, Korea
}

\begin{abstract}
This paper presents a zero-voltage-switching (ZVS) boost converter using a coupled inductor. It utilizes an additional winding to the boost inductor and an auxiliary diode. The ZVS characteristic of the proposed converter reduces the switching losses of the active power switches and raises the power conversion efficiency. The principle of operation and a system analysis are presented. The theoretical analysis and performance of the proposed converter were verified with a $100 \mathrm{~W}$ experimental prototype operating at a $107 \mathrm{kHz}$ switching frequency.
\end{abstract}

Key Words: Boost converter, Coupled inductor, DC-DC converter, Reverse recovery, Zero-voltage-switching

\section{INTRODUCTION}

DC-DC step-up converters are widely used in industrial applications such as computer periphery power supplies, servomotor drives, car auxiliary power supplies, and medical equipment [1], [2]. A continuous conduction mode (CCM) boost converter can be selected as a possible candidate for a step-up converter with a continuous input current. Since a continuous input current can simplify the input filter stage, it is one of the major advantages of this solution. However, its switching losses and the reverse-recovery problem of the output diode degrade system performance in terms of efficiency and electromagnetic interference noise [3]. The moment the power switch turns on, the reverse recovery phenomenon of the output diode occurs. During this interval, the switch is submitted to a high current change rate and a high peak of reverse recovery current. In order to reduce the switching loss, the switching frequency should be lowered. However, lowering the switching frequency raises the system volume and cost. Therefore, an efficient method to obtain soft-switching operation of the switches and to alleviate the reverse recovery problem of the power diode is required. In [4], a new boost converter with a ripple free input current was suggested. In the new boost converter, an extra LC circuit with coupled inductors was utilized. The ripple component of the input current was reduced by carefully designing the parameters of the coupled inductor. However, the efficiency could not be improved due to the switching losses of the power switch. To increase the efficiency and power conversion density, the soft-switching technique is required in DC/DC converters [5]-[11]. In [9], a new soft-switching technique for buck, boost, and buck-boost

Manuscript received Apr. 23, 2010; revised Oct. 5, 2010

$\dagger$ Corresponding Author: hldo@snut.ac.kr

Tel: +82-2-970-6463, Fax: +82-2-979-7903, Seoul Nat'l Univ. of Sci. and tech

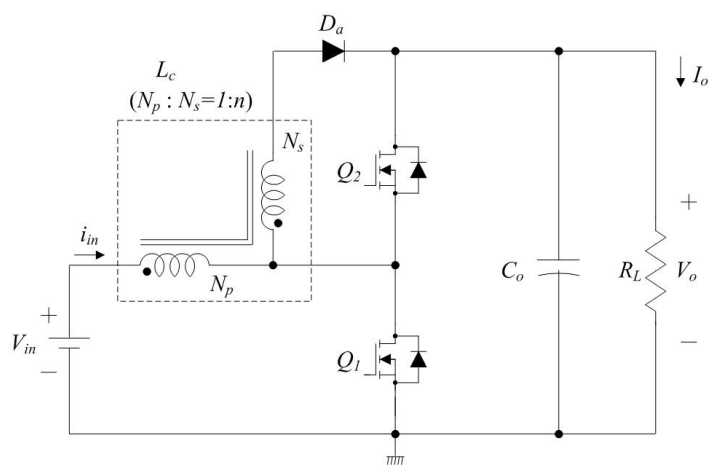

Fig. 1. Proposed ZVS boost converter.

converters was suggested. This technique utilizes an auxiliary circuit consisting of a coupled inductor, an auxiliary inductor, and an auxiliary diode. It provides the ZVS characteristic and its main inductor current is kept in CCM. However, two magnetic components lower the power density. In [10], [11], soft-switching boost converters with a single switch were suggested. They can be a cost-effective solutions due to the single power switch. However, there are four power diodes and it may increase the conduction loss.

In order to overcome these problems, a ZVS boost converter with a coupled inductor is proposed. The ZVS characteristic of the proposed boost converter reduces the switching losses and raises the overall efficiency. Moreover, since the ZVS characteristic is achieved by adding an additional winding to the boost inductor, there is only one magnetic component. The reverse-recovery of the auxiliary diode is alleviated due to the leakage inductance of the coupled inductor. The theoretical analysis is verified by a $100 \mathrm{~W}$ experimental prototype with 24V-to-86V conversion.

This paper is organized as follows. An analysis of the 


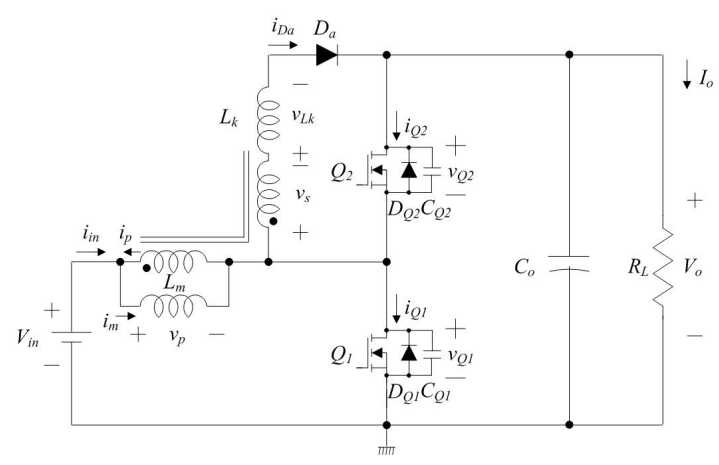

Fig. 2. Equivalent circuit of the proposed converter.

proposed converter is provided in Section II. The design parameters of the proposed converter are presented in Section III. The experimental results are shown in Section IV and some conclusions are given in Section V.

\section{Analysis of The Proposed Converter}

Similar to a conventional CCM boost converter, the ZVS boost converter provides a continuous input current and has the same voltage gain. However, the ZVS operation of the power switches is accomplished by adopting an additional winding of the boost inductor and an auxiliary diode. The ZVS operation of the proposed converter can raise the overall efficiency and lower the noise. As shown in Fig. 1, the proposed ZVS boost converter consists of a coupled inductor $L_{c}$, a lower switch $Q_{1}$, an upper switch $Q_{2}$, an auxiliary diode $D_{a}$ and an output capacitor $C_{o}$. The switches $Q_{1}$ and $Q_{2}$ are operated asymmetrically and the duty ratio $D$ is based on the switch $Q_{1}$. An equivalent circuit diagram of the proposed ZVS boost converter is shown in Fig. 2. The diodes $D_{Q 1}$ and $D_{Q 2}$ are the intrinsic body diodes of $Q_{1}$ and $Q_{2}$, respectively. The capacitors $C_{Q 1}$ and $C_{Q 2}$ are the parasitic output capacitances of $Q_{1}$ and $Q_{2}$. The coupled inductor $L_{c}$ is modeled as the magnetizing inductance $L_{m}$, the leakage inductance $L_{k}$, and the ideal transformer, which has a turn ratio of 1:n $\left(n=N_{s} / N_{p}\right)$. The key waveforms of the proposed ZVS boost converter are shown in Fig. 3. The magnetizing current $i_{m}$ flowing through the magnetizing inductance $L_{m}$ varies from its minimum value $I_{m 2}$ to its maximum value $I_{m 1}$. The auxiliary diode current $i_{D a}$ varies from zero to its maximum value $I_{D a}$. The operation of the proposed ZVS boost converter stage in one switching period $T_{s}$ can be divided into five modes as shown in Fig. 4. Before $t_{0}$, the upper switch $Q_{2}$ and the auxiliary diode $D_{a}$ are conducting.

Mode $1\left[t_{0}, t_{1}\right]$ : At $t_{0}$, the switch $Q_{2}$ is turned off. Then, the input current $i_{\text {in }}$ and the auxiliary diode current $i_{D a}$ start to charge $C_{Q 2}$ and discharge $C_{Q 1}$. Therefore, the voltage $v_{Q 1}$ across $Q_{1}$ starts to fall and the voltage $v_{Q 2}$ across $Q_{2}$ starts to rise. With the assumption that the input current $i_{\text {in }}$ and the auxiliary diode $i_{D a}$ are as constant as $I_{m 2}-n I_{D a}$ and $I_{D a}$ during this mode, the transition interval $T_{t 1}$ can be determined as

$$
T_{t 1}=\frac{\left(C_{Q 1}+C_{Q 2}\right) V_{o}}{(1+n) I_{D a}-I_{m 2}} .
$$

Since the output capacitances $C_{Q 1}$ and $C_{Q 2}$ of the switches are very small, the transition interval $T_{t 1}$ is very short and it

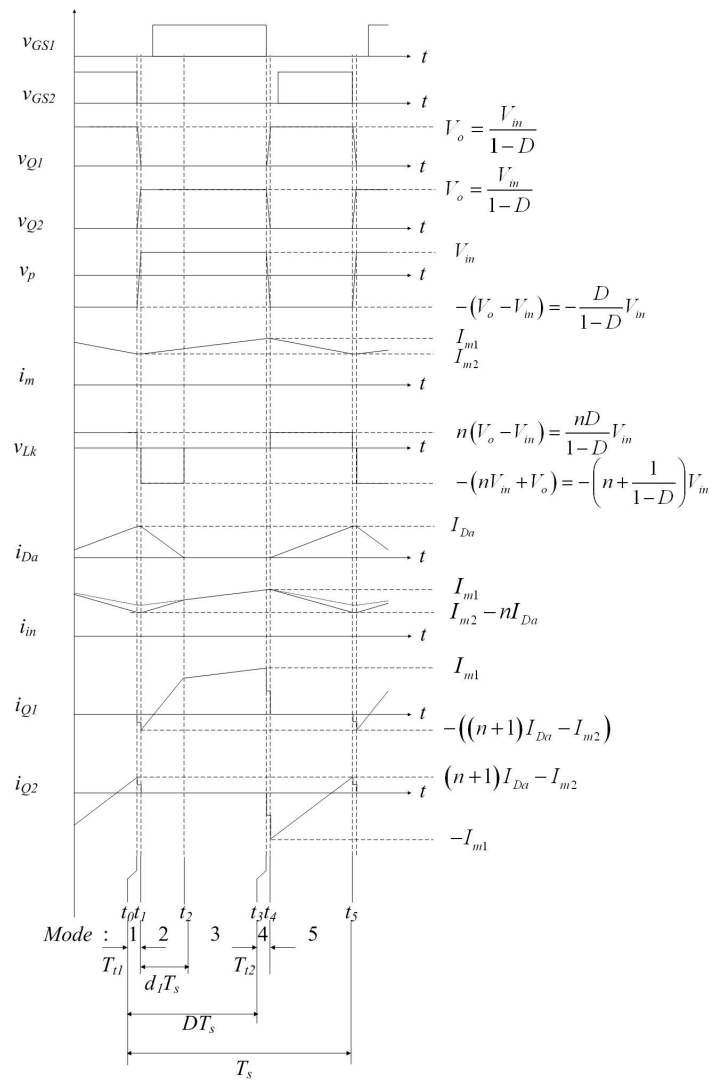

Fig. 3. Key waveforms of the proposed converter.

can be neglected. Therefore, the currents $i_{m}$ and $i_{D a}$ can be considered to have constant values during Mode 1.

Mode $2\left[t_{1}, t_{2}\right]$ : At $t_{1}$, the voltage $v_{Q 1}$ across the lower switch $Q_{1}$ becomes zero and the body diode $D_{Q 1}$ is turned on. Then, the gate signal is applied to the switch $Q_{1}$. Since the current has already flown through the body diode $D_{Q 1}$ and the voltage $v_{Q 1}$ is maintained at zero before the switch $Q_{1}$ is turned on, the zero-voltage turn-on of $Q 1$ is achieved. Since the voltage $v_{p}$ across the magnetizing inductance $L_{m}$ is $V_{i n}$, the magnetizing current $i_{m}$ increases linearly from its minimum value $I_{m 2}$ as follows:

$$
i_{m}(t)=I_{m 2}+\frac{V_{i n}}{L_{m}}\left(t-t_{1}\right) .
$$

Since the voltage $v_{L k}$ across the leakage inductance $L_{k}$ is $-\left(n V_{i n}+V_{o}\right)$, the auxiliary diode current $i_{D a}$ linearly decreases from its maximum value $I_{D a}$ as follows:

$$
i_{D a}(t)=I_{D a}-\frac{n V_{i n}+V_{o}}{L_{k}}\left(t-t_{1}\right) .
$$

From (2) and (3), the input current $i_{i n}$ and the lower switch current $i_{Q 1}$ are determined as:

$$
\begin{aligned}
& \quad \begin{array}{l}
i_{i n}(t)=i_{m}(t)-i_{p}(t) \\
\quad=I_{m 2}-n I_{D a}+\frac{V_{i n}}{L_{m}}\left(t-t_{1}\right)+n \cdot \frac{n V_{i n}+V_{o}}{L_{k}}\left(t-t_{1}\right)
\end{array} \\
& \begin{array}{l}
i_{Q 1}(t)= \\
\quad=i_{i n}(t)-i_{D a}(t) \\
\quad=I_{m 2}-(n+1) I_{D a}+\left(\frac{V_{i n}}{L_{m}}+(n+1) \cdot \frac{n V_{i n}+V_{o}}{L_{k}}\right)\left(t-t_{1}\right)
\end{array} .
\end{aligned}
$$

Mode $3\left[t_{2}, t_{3}\right]$ : At $t_{2}$, the auxiliary diode current $i_{D a}$ decreases to zero and the diode $D_{a}$ is turned off. Since 

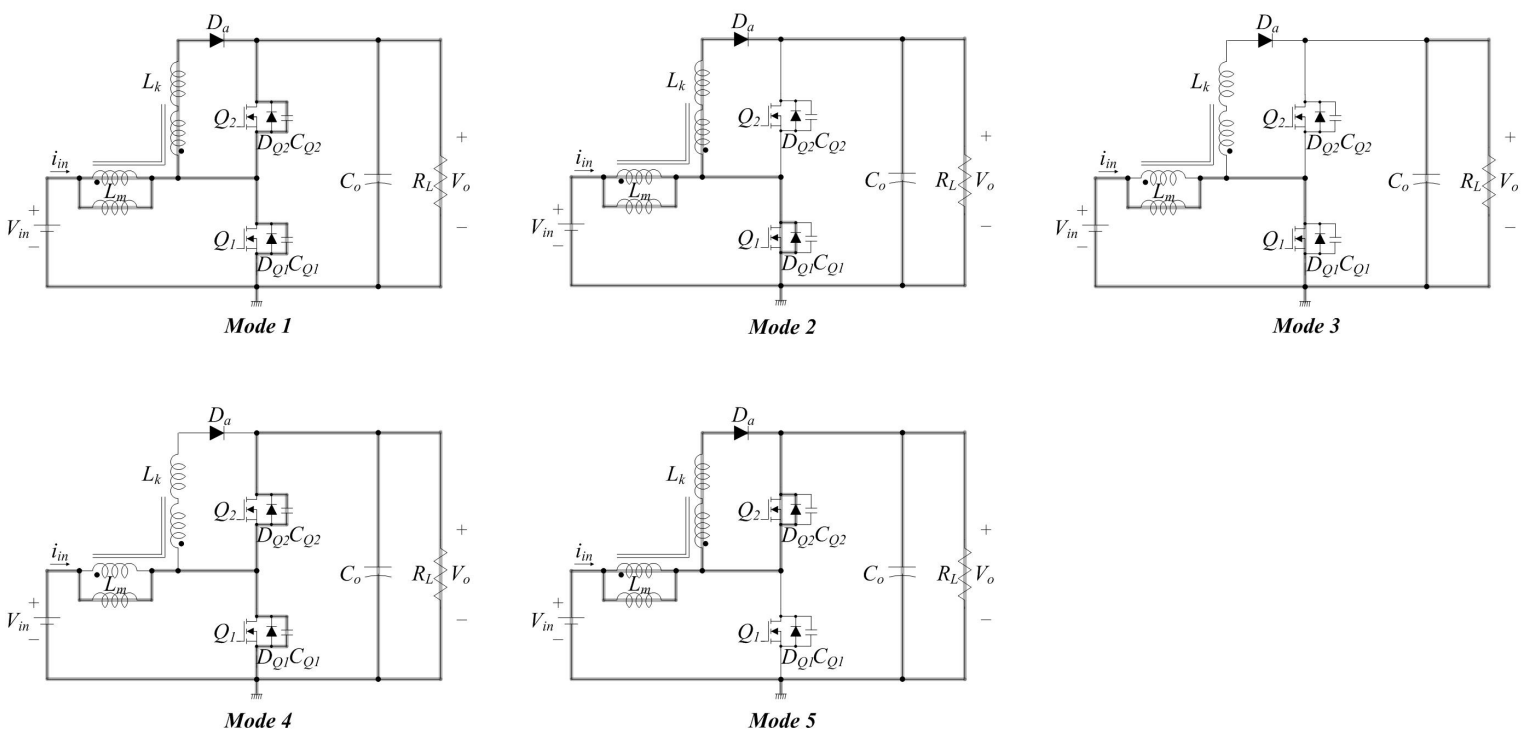

Fig. 4. Operating modes.

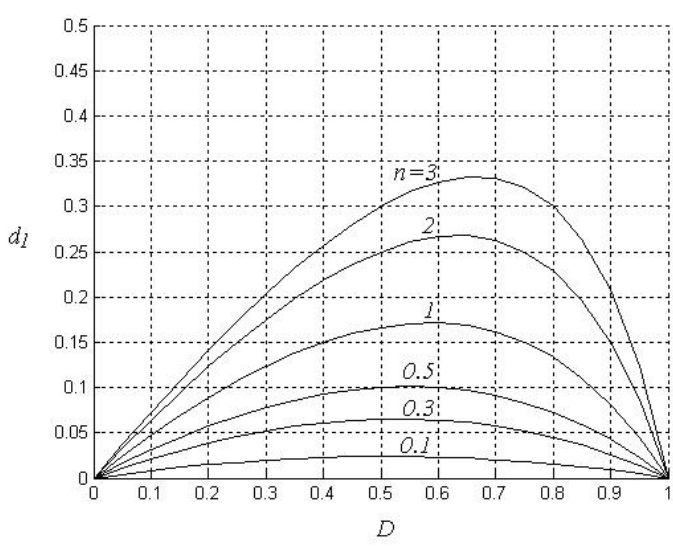

Fig. 5. Auxiliary diode current reset timing ratio $d_{1}$ according to duty cycle $D$.

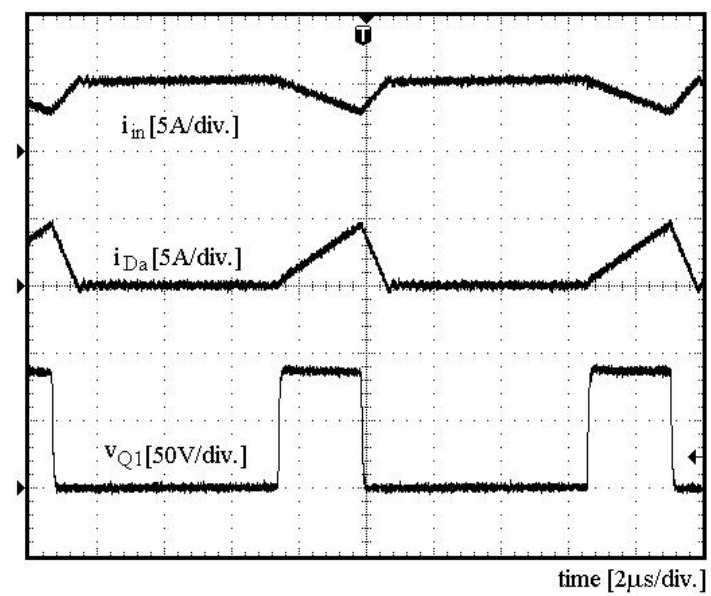

Fig. 6. Experimental waveforms: $i_{i n}, i_{D a}$, and $v_{Q 1}$.

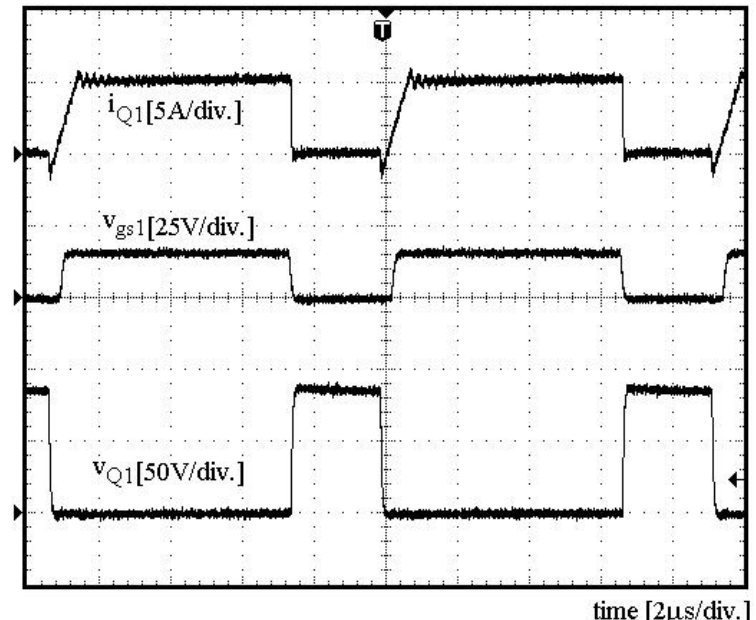

(a)

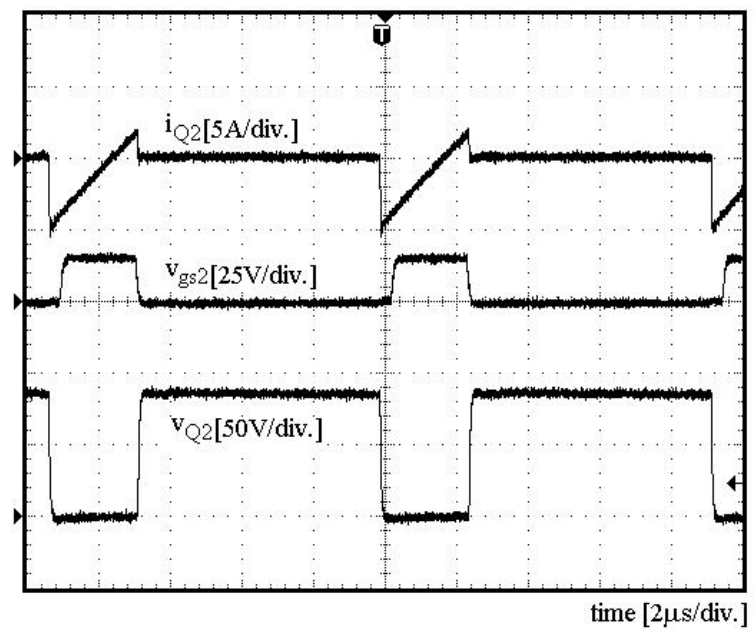

(b)

Fig. 7. Experimental waveforms: (a) $i_{Q 1}, v_{g s 1}$, and $v_{Q 1}$; (b) $i_{Q 2}, v_{g s 2}$, and $v_{Q 2}$. 


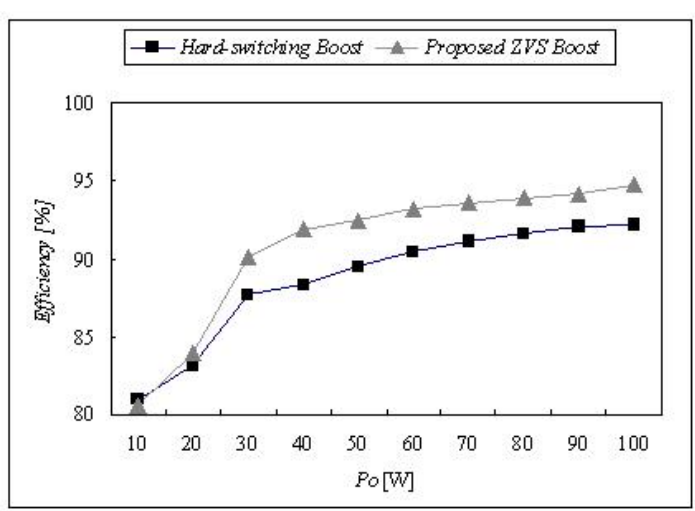

Fig. 8. Measured efficiency.

the changing rate of the diode current $i_{D a}$ is controlled by the leakage inductance of the coupled inductor, its reverse recovery problem is significantly alleviated. Since the voltage $v_{p}$ across the magnetizing inductance $L_{m}$ is the input voltage $V_{i n}$, the magnetizing current $i_{m}$ increases linearly with the same slope as in Mode 2 as follows:

$$
i_{m}(t)=i_{m}\left(t_{2}\right)+\frac{V_{i n}}{L_{m}}\left(t-t_{2}\right) .
$$

Since the auxiliary diode current $i_{D a}$ is zero, the input current $i_{i n}$ and the lower switch current $i_{Q 1}$ are equal to the magnetizing current $i_{m}$. At the end of this mode, the magnetizing current $i_{m}$ arrives at its maximum value $I_{m 1}$.

Mode $4\left[t_{3}, t_{4}\right]$ : At $t_{3}$, the switch $Q_{1}$ is turned off. Then, the magnetizing current $i_{m}$ starts to charge $C_{Q 1}$ and discharge $C_{Q 2}$. Therefore, the voltage $v_{Q 1}$ across $Q_{1}$ starts to rise and the voltage $v_{Q 2}$ across $Q_{2}$ starts to fall. With the same assumption as in Mode 1, the transition interval $T_{t 2}$ can be determined as

$$
T_{t 2}=\frac{\left(C_{Q 1}+C_{Q 2}\right) V_{o}}{I_{m 1}} .
$$

Similar to Mode 1 , the transition interval $T_{t 2}$ is very short and it can be neglected.

Mode $5\left[t_{4}, t_{5}\right]$ : At $t_{4}$, the voltage $v_{Q 2}$ across the upper switch $Q_{2}$ becomes zero and the body diode $D_{Q 2}$ is turned on. Then, the gate signal is applied to the switch $Q_{2}$. Since the current has already flown through the body diode $D_{Q 2}$ and the voltage $v_{Q_{2}}$ is maintained at zero before the switch $Q_{2}$ is turned on, the zero-voltage turn-on of $Q_{2}$ is achieved. Since the voltage $v_{p}$ across the magnetizing inductance $L_{m}$ is $-\left(V_{o}-V_{i n}\right)$, the magnetizing current $i_{m}$ decreases linearly from its maximum value $I_{m 1}$ as follows:

$$
i_{m}(t)=I_{m 1}-\frac{V_{o}-V_{i n}}{L_{m}}\left(t-t_{4}\right) .
$$

Since the voltage $v_{L k}$ across the leakage inductance $L_{k}$ is $n\left(V_{o}-V_{i n}\right)$, the auxiliary diode current $i_{D a}$ linearly increases from zero as follows:

$$
i_{D a}(t)=\frac{n\left(V_{o}-V_{i n}\right)}{L_{k}}\left(t-t_{4}\right) .
$$

From (8) and (9), the input current $i_{i n}$ and the lower switch current $i_{Q 1}$ are determined as

$$
\begin{aligned}
& i_{i n}(t)=i_{m}(t)-i_{p}(t) \\
& \quad=I_{m 1}-\frac{V_{o}-V_{i n}}{L_{m}}\left(t-t_{4}\right)-\frac{n^{2}\left(V_{o}-V_{i n}\right)}{L_{k}}\left(t-t_{4}\right),
\end{aligned}
$$

$$
\begin{aligned}
& i_{Q 1}(t)=i_{i n}(t)-i_{D a}(t) \\
& \quad=I_{m 1}-\left(\frac{1}{L_{m}}+\frac{n(n+1)}{L_{k}}\right)\left(V_{o}-V_{i n}\right)\left(t-t_{4}\right) .
\end{aligned}
$$

\section{DESIGN PARAMETERS}

\section{A. Voltage gain}

Referring to the voltage waveform $v_{p}$ across the magnetizing inductance $L_{m}$ in Fig. 3, the volt-second balance law gives

$$
V_{\text {in }} D T_{s}-\left(V_{o}-V_{\text {in }}\right)(1-D) T_{s}=0 .
$$

From (12), the voltage gain of the proposed ZVS boost converter is obtained by

$$
\frac{V_{o}}{V_{\text {in }}}=\frac{1}{1-D},
$$

which is the same as that of a conventional CCM boost converter.

\section{B. Auxiliary diode current reset timing ratio $d_{1}$}

By applying the volt-second balance law to the voltage waveform $v_{L k}$ across the leakage inductance $L_{k}$, the auxiliary diode current reset timing ratio $d_{1}$ is determined by

$$
d_{1}=\frac{n D(1-D)}{n(1-D)+1} \text {. }
$$

Fig. 5 shows the theoretical $d_{1}$ according to $D$ with several different values of $n$. After the duty cycle is determined, the turn ratio $n$ can be selected for a predetermined auxiliary diode current reset timing ratio $d_{1}^{*}$ as follows:

$$
n=\frac{d_{1}^{*}}{\left(D-d_{1}^{*}\right)(1-D)} .
$$

The predetermined auxiliary diode current reset timing ratio $d_{1}^{*}$ should be larger than the dead times of $Q_{1}$ and $Q_{2}$ for proper ZVS operation.

\section{Maximum auxiliary diode current $I_{D a}$}

From (9) and (13), the maximum auxiliary diode current $i_{D a}$ is obtained by

$$
I_{D a}=\frac{n D V_{i n} T_{s}}{L_{k}} .
$$

\section{ZVS conditions}

From Fig. 3, the ZVS condition for $Q_{2}$ is given by

$$
I_{m 1}>0 .
$$

From (17), it can be seen that the ZVS of $Q_{2}$ is easily obtained. Similarly, for the ZVS of $Q_{1}$, the following condition should be satisfied.

$$
(n+1) I_{D a}-I_{m 2}>0 .
$$

The inequality (18) can be rewritten by

$$
L_{k}<\frac{n(n+1) D V_{i n} T_{s}}{I_{m 2}} .
$$

With the assumption that the minimum magnetizing current $I_{m 2}$ is similar to the average input current, the leakage inductance $L_{k}$ of the coupled inductor can be designed by

$$
L_{k}<\frac{n(n+1) \eta D V_{i n}^{2} T_{s}}{P_{o}},
$$

where $P_{o}$ is the output power and $h$ is the efficiency. 


\section{E. Input current ripple $\Delta i_{\text {in }}$}

From Fig. 3, the input current ripple is determined as

$$
\Delta i_{i n}=I_{m 1}-I_{m 2}+n I_{D a}=\left(\frac{V_{i n}}{L_{m}}+\frac{n^{2} V_{i n}}{L_{k}}\right) D T_{s} .
$$

In order to reduce the input current ripple $\Delta i_{i n}$ below a specific value $\Delta i_{i n}^{*}$, the magnetizing inductance $L_{m}$ of the coupled inductor should satisfy the following condition:

$$
L_{m}>\frac{D V_{i n} T_{S}}{\Delta i_{i n}^{*}-\frac{n^{2} D V_{i n} T_{s}}{L_{k}}} .
$$

\section{EXPERIMENTAL RESULTS}

A prototype ZVS boost converter using a coupled inductor is implemented. The input voltage $V_{\text {in }}$ is $24 \mathrm{~V}$ and the output voltage $V_{o}$ is $86 \mathrm{~V}$. The maximum output power is $100 \mathrm{~W}$. The predetermined auxiliary diode current reset timing ratio $d l^{*}$ is selected as 0.09 . Since the theoretical duty cycle is calculated as 0.72 from (13), the turn ratio $n$ of the coupled inductor is selected as 0.5 according to (15). The switching frequency is selected as $107 \mathrm{kHz}$. From (20), the leakage inductance $L_{k}$ is determined as $20 u H$. With a selection of $\Delta i_{i n}^{*}$ as $2.2 A$, the magnetizing inductance $L_{m}$ is selected as $810 u H$ from (22).

Fig. 6 shows the input currents $i_{i n}$, the auxiliary diode current $i_{D a}$, and the voltage $v_{Q 1}$. The input current is continuous and its ripple component is around $2 \mathrm{~A}$. The ripple component of the input current can be controlled by the magnetizing inductance $L_{m}$. The leakage inductance $L_{k}$ of the coupled inductor $L_{c}$ controls the changing rate of the auxiliary diode current. Therefore, the reverse recovery of the auxiliary diode $D_{a}$ is significantly alleviated. Fig. 7 shows the ZVS of $Q_{1}$ and $Q_{2}$. In Fig. 7(a), since the switch current $i_{Q 1}$ flows through the body diode of $Q_{1}$ and the voltage $v_{Q 1}$ goes to zero before the gate pulse $v_{G S 1}$ is applied to $Q_{1}$, the ZVS of $Q_{1}$ is obtained. Similarly, the ZVS of $Q_{2}$ is obtained as shown in Fig. 7(b). It can be seen that the experimental waveforms in Fig. 6 and 7 agree with the theoretical analysis suggested in sections II and III. Fig. 8 shows the measured efficiency of the proposed converter compared with that of a conventional boost converter. It exhibits an efficiency of $94.7 \%$ under the full load condition. Due to its soft-switching characteristic, the overall efficiency is improved by $2.5 \%$ under the full load condition. The proposed ZVS boost converter still provides a continuous input current. Moreover, the ZVS operation of the power switches raises the overall efficiency and the reverse recovery of the auxiliary diode is alleviated due to the leakage inductance of the coupled inductor.

\section{CONCLUSIONS}

A ZVS boost converter using a coupled inductor has been proposed. The voltage gain of the proposed ZVS boost converter is equal to that of a conventional CCM boost converter.
It also provides a continuous input current. Moreover, it improves overall efficiency due to the ZVS operation of the power switches. Therefore, the proposed ZVS boost converter is suitable for industrial applications that require a step-up function and a continuous input current characteristic.

\section{ACKNOWLEDGMENT}

This work was supported by the Korea Research Foundation (KRF) grant funded by the Korea government (MEST) (No. 2009-0069551).

\section{REFERENCES}

[1] M. Zhu, and F. L. Luo, "Series SEPIC implementing voltage-lift technique for DC-DC power conversion," IET Power Electronics, Vol. 1, No. 1, pp. 109-121, Mar. 2008

[2] F. L. Luo, "Re-lift circuits: a new dc-dc step-up boost converter," IET Electronics Letters, Vol. 33, No, 1, pp. 5-7, Jan. 1997.

[3] Q. Zhao, F. Tao, F. C. Lee, P. Xu, and J. Wei, "A simple and effective to alleviate the rectifier reverse-recovery problem in continuous-currentmode boost converter," IEEE Power Electronics, Vol. 16, No. 5, pp. 649-658, Sep. 2001.

[4] D. K. W. Cheng, X. C. Liu, and Y. S. Lee, "A new improved boost converter with ripple free input current using coupled inductors," Power Electronics and Variable Speed Drives 7th International Conference, pp. 592-599, 1998

[5] B. -R. Lin, J. -Y. Dong, and J. -J. Chen, "Active-clamp ZVS converter with step-up voltage conversion ratio," International Journal of Electronics, Vol. 96, pp. 491-502, May 2009.

[6] B. -R. Lin and C. -L. Huang, "Analysis and implementation of a dualoutput LLC resonant converter," International Journal of Electronics, Vol. 96, pp. 733-747, Jul. 2009.

[7] B. -R. Lin, J. -J. Chen, and H. -K. Chiang, "Analysis of a new ZVS converter with output voltage doubler," International Journal of Electronics, Vol. 96, pp. 1057-1070, Oct. 2009.

[8] M. R. Amini and H. Farzanehfard, "Novel family of PWM softsingle-switched DC-DC converters with coupled inductors," IEEE Trans. Industrial Electronics, Vol. 56, No. 6, pp. 2108-2114, Jun. 2009.

[9] Y. Zhang and P. C. Sen, "A New Soft-switching Technique for Buck, Boost, and Buck-Boost Converters," IEEE Trans. Industry Applications, Vol. 39, No.6, pp. 1775-1782, Nov./Dec. 2003.

[10] Mantaro Nakamura, Koki Ogura and Mutsuo Nakaoka, "Soft-switching PWM Boost Chopper-Fed DC-DC Power Converter with Load Side Auxiliary Oassive Resonant Snubber," Journal of Power Electronics, Vol. 4, No.3, pp. 161-168, Jul. 2004.

[11] Jun-Ho Kim, Doo-Yong Jung, Sang-Hoon Park, Chung-Yeun Won, Yong-Chae Jung, and Su-Won Lee, "High Efficiency Soft-switching Boost Converter Using a Single Switch," Journal of Power Electronics, Vol. 9, No. 6, pp. 929-939, Dec. 2009.

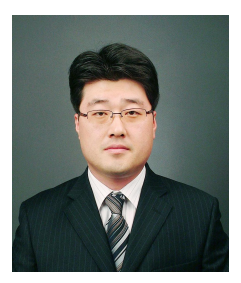

Hyun-Lark Do received his B.S. from Hanyang University, Seoul, Korea, in 1999, and his M.S. and Ph.D. in Electronic and Electrical Engineering from the Pohang University of Science and Technology, Pohang, Korea, in 2002 and 2005, respectively. From 2005 to 2008, he was a Senior Research Engineer with the PDP Research Laboratory, LG Electronics Inc., Gumi, Korea. Since 2008, he has been with the Department of Electronic and Information Engineering, Seoul National University of Science and Technology, where he is currently a Professor. His research interests include the modeling, design, and control of power converters, soft-switching power converters, resonant converters, power factor correction circuits, and driving circuits for plasma display panels. 